\title{
ANÁLISE MORFOMÉTRICA DE BACIAS DE DRENAGEM E SUA RELAÇÃO COM A ESTRUTURA GEOLÓGICA, SERRA DO ESPINHAÇO MERIDIONAL-MG
}

\author{
MORPHOMETRIC ANALYSIS OF DRAINAGE BASIN AND ITS \\ RELATIONSHIP WITH THE GEOLOGICAL STRUCTURE, SERRA DO \\ ESPINHAÇO MERIDIONAL-MG
}

\author{
Bráulio Magalhães Fonseca \\ Instituto de Geociências - Universidade Federal de Minas Gerais \\ Av. Antônio Carlos, 6.627 - Pampulha - Belo Horizonte/MG, Cep: 31270-901, Brasil. \\ E-mail: brauliomagalhaes@ufmg.br \\ Cristina Helena Ribeiro Rocha Augustin \\ Departamento de Geografia - Universidade Federal de Minas Gerais \\ Av. Antônio Carlos, 6.627 - Pampulha - Belo Horizonte/MG, Cep: 31270-901, Brasil. \\ E-mail: chaugustin@hotmail.com
}

\section{Informações sobre o Artigo}

Data de Recebimento:

10/05/2012

Data de Aprovação:

29/04/2014

\section{Palavras-chave:}

Geoprocessamento, morfometria da bacia de drenagem, morfologia do relevo, evolução da rede de drenagem, litoestrutura.

\section{Keywords:}

Reprocessing, morfometry of drainage basin, relief morphology, drainage basin evolution, litho structure.

\section{Resumo}

A relação entre a dinâmica da rede de drenagem e o substrato geológico constitui uma abordagem há muito estabelecida na literatura geomorfológica. Nas últimas décadas, o desenvolvimento de instrumental do Geoprocessamento tem permitido a realização de análises de importantes aspectos que revelam essa relação, lançando mão de quantificações e elementos de detalhe que enriquecem esses estudos. O principal objetivo deste trabalho é o de obter uma melhor compreensão da dinâmica de duas bacias de drenagem a partir da análise de parâmetros morfológicos e morfométricos e sua relação com elementos litoestruturais da área de estudo. As duas bacias drenagem encontram-se localizadas nas bordas leste (Rio Jequitinhonha) e oeste (Rio Pardo) da Serra do Espinhaço Meridional, em rochas do Supergrupo Espinhaço, formado predominantemente por quartzitos, dobrados e falhados no Neoproterozóico durante o Brasiliano (650-530 Ma), que deformou a porção móvel da faixa Móvel do Araçuaí, a leste do cráton São Francisco, no estado de Minas Gerais. Os resultados de análises morfométricas e dos lineamentos estruturais com o auxílio de técnicas de geoprocessamento e sensoriamento remoto permitiram comprovar a estreita relação entre as características dessas redes de drenagem e os elementos litoestruturais presentes na área estudada.

\section{Abstract}

The relationship between drainage basin dynamics and the characteristics of underlying rocks is since long already established in the geomorphic literature. 
However, in the last decades the evolution of geoprocessing techniques has allowed the analysis of important aspects of this relationship that take into account quantification and detailed elements which improve this type of studies. The main objective of this research is to get a better understanding of the dynamic of the two drainage basins, on the basis of the relation between the morphological and morphometric analysis and the morphoestructural and lithological elements present in the study area. Both basins are located at the eastern (Rio Jequitinhonha), and western (Rio Pardo) border of the Espinhaço Meridional Range, formed predominantly of quartzite from the Espinhaço Supergroup which were folded and faulted in the Neoproterozoic during the Brasiliano Cycle (650530Ma), deforming the mobile portion of the Faixa Araçuí at the eastern portion of the São Francisco Craton, in Minas Gerais State. The Espinhaço Supergroup is composed of three main lithostratighraphic unities, of which the most important are quartzite because of its spatial extension. Morphometric analysis as well as the analysis of the structural lineaments supported by geoprocessing and remote sensing techniques allow to assuming that there is a close relationship between the drainage network characteristics and the litho-structural elements present in the study area.

\section{Introdução}

Análises quantitativas sistemáticas do relevo com aplicação inicial para estudos hidrológicos tiverem início a partir dos estudos de Horton e Strahler entre as décadas de 1940s e 1950 do século passado (HORTON, 1945; STRAHLER, 1952a, 1952b; GUSTAVSSON, 2006). Essas análises lançaram as bases para a realização de trabalhos com abordagem morfométrica que muito têm contribuído para o entendimento da dinâmica das bacias e sua relação com os fatores que as influenciam, com destaque para os elementos da geologia (LEOPOLD, et al., 1964; HOWARD, 1967; REED e SIGAFOOS, 1970; HOBSON, 1972; GREGORY e WALLING, 1973; O'LEARY, 1976; LEOPOLD e BULL, 1979; MILLER et al., 1990; HURTREZ e LUCAZEAU, 1999; LUO e STEPINSKI, 2008b).

Embora o substrato rochoso seja reconhecido como um dos fatores que influenciam no desenvolvimento das bacias hidrográficas e na elaboração das formas de relevo, esta relação nem sempre tem sido simples de ser estabelecida. De acordo com Gerrard (2008), Johnton, em 1929, foi um dos primeiros a utilizar grandes unidades estruturais como bases analíticas na definição das formas de relevo. Também Miller (1953, apud GERRARD, 2008) estabeleceu relações quantitativas entre formas de relevo e estruturas geológicas, dando continuidade a trabalhos realizados por Powell em 1875, ao demonstrar que o comprimento dos canais e das bacias de drenagem era inversamente proporcional às inclinações de flancos de um relevo homoclinal. Penck (1953) foi, no entanto, um dos primeiros a propor uma análise mais integrada entre geologia e formas de relevo, ao associar processos endógenos e características do relevo ao tipo de rocha sobre o qual este se desenvolveu (GERRARD, 2008). Publicações mais recentes retomam essas análises com ênfase em diversos aspectos da influência litológica e estrutural nas cadeias de montanhas (DEMEK, 1982; MILLER et al., 1990; SUMMERFIELD, 1999; LUO e STEPINSKI, 2008b; BLOOMFIELD, et al., 2011).

Outros trabalhos importantes foram publicados utilizando a relação entre os elementos da geologia e as características de bacias de drenagem (McKEOWN, et al., 1988; DEFFONTAINES e CHOROWICZ, 1991; MAYER, 1992; BAKER, 1998; WHIPPLEET et al., 2000; LAMB e DIETRICH, 2009; PECKHAM, 2009, 2014). Entre as principais contribuições publicadas a partir da década de 1970, destaca-se a de Hack em 1960 e 1973, que desenvolveu o índice que leva seu nome, e que permite comparações de energia dentro dos sistemas das bacias de drenagem, tornando possível que se estabeleça comparações entre elas, facilitando interpretações da influência da geologia.

Modelos numéricos e o desenvolvimento das ferramentas do Sistema de Informação Geográfica (SIG), entre elas, o Modelo Digital de Terreno (MDT), permitiram que fosse utilizado um maior número de critérios quantitativos para as análises de bacias e a associação dos mesmos com elementos da base geológica (HARBOR, 1992; van der BEEK e BRAUN, 1998; BOULTON e WHITTAKER, 2009; TUCKER e HANCOCK, 2010; TAMMA RAO et al., 2012; KUMAR, 
2013). Isto teve efeito sobre o número de publicações que utilizam essas ferramentas na análise do relevo em sua associação com a geologia.

No Brasil, as primeiras abordagens utilizando a base geológica como um dos elementos importantes para o mapeamento geomorfológico foram realizadas pelo Projeto RADAM (entre 1970 e 1985), em escalas de pouco detalhe, mas criando metodologia e abrindo perspectivas para que outras abordagens pudessem ser propostas, como a de Ross (1992).

O desenvolvimento das ferramentas do Geoprocessamento também teve efeito direto sobre as análises do modelado do relevo, com as publicações, entre outras, de VENEZIANI, 1987; AMARO e STRIEDER, 1994; CENTENO, 2003; VALERIANO e CARVALHO JUNIOR, 2003; ETCHEBEHERE, et al., 2004; CARVALHO e LATRUBESSE, 2004; CARDOSO et al., 2006; SALLUN e SUGUIO, 2007; SAMPAIO e AUGUSTIN, 2008; SAMPAIO e AUGUSTIN, 2014; ANDRADES FILHO e FONSECA, 2009; AQUINO et al., 2009; HARTWIG e RICCOMINI, 2010; FONSECA, 2010; FONSECA e AUGUSTIN, 2011; SANTOS et al., 2011; LIMA et al., 2011; CAMOLEZI et al., 2012.

As bacias de drenagem em estudo encontram-se localizadas na Serra do Espinhaço Meridional (SdEM), que constitui um conjunto de serras (Figura 1) com fisiografia mais compatível com características de planalto (SAADI, 1995). Ela faz parte da faixa móvel do Araçuaí, deformada durante o Evento Brasiliano no Neoproterozóico (650-530 Ma), dando origem a um importante sistema de falhas e fraturas que, juntamente com os estrados dobrados, marcam a paisagem maciço (AUGUSTIN et al., 2011). O tipo de relevo, bem como sua evolução, evidencia importantes influências litoestruturais tanto no tipo e intensidade dos processos que atuam sobre este maciço, quanto nas diferentes respostas às taxas de erosão ao longo da sua esculturação.

Com o objetivo de analisar a influência da litologia e estrutura nas características das formas de relevo e na evolução dessas duas bacias hidrográficas buscou-se levantar uma série de parâmetros morfométricos e correlaciona-los aos elementos litológicos e de lineamentos estruturais presentes nas respectivas áreas das bacias.

A utilização desses instrumentos tem sido apontada pela literatura citada nesta introdução, como capaz de fornecer uma base analítica importante para o tipo de a abordagem proposta neste estudo. Neste sentido, os resultados servem também como indicadores da capacidade dos mesmos para atender aos objetivos da pesquisa e eficiência quanto ao tipo de dado e análise, na busca por uma melhor compreensão da dinâmica geomorfológica das bacias de drenagem em questão.

\section{Área de estudo}

A área de estudo compreende duas das mais importantes bacias de drenagem da serra do Espinhaço: a do rio Pardo, com $2.029 \mathrm{Km}^{2}$ e a do Alto Jequitinhonha, com $2.054 \mathrm{~km}^{2}$. Esta última, na borda leste, desenvolve-se completamente sobre substrato geológico formado pelas rochas do Supergrupo Espinhaço (FONSECA e AUGUSTIN, 2011). A bacia do Rio Pardo, localizada na borda oeste, é predominantemente formada por quartzitos do Supergrupo Espinhaço contando, no entanto, com a presença de rochas carbonáticas do Grupo Bambuí na sua porção oeste (FONSECA, 2010; FONSECA e AUGUSTIN, 2011; FONSECA et al., 2013/2014).

As duas bacias encontram-se totalmente localizadas no domínio do Espinhaço Meridional, a porção da Serra do Espinhaço abaixo do paralelo $17^{\circ} \mathrm{S}$, dento dos limites do estado de Minas Gerais (Figura 1). A base geológica de ambas as bacias é formada principalmente por rochas do Supergrupo Espinhaço, quartzitos com graus diferenciados de composição de quartzo. Características estruturais herdadas das fases deposicionais e, posteriormente, das deformacionais do Evento Brasiliano, favoreceram o aparecimento de um conjunto de dobras, falhas e fraturas presentes neste litótipo (AUGUSTIN, 1995; AUGUSTIN et al., 2011).

Esses elementos da paisagem, juntamente com uma expressiva precipitação média anual, criam condições de retenção de água, o que faz da porção meridional do Espinhaço uma importante área de recarga e local de um expressivo número de cabeceiras de drenagem.

A média de precipitação anual nas duas bacias é de aproximadamente $1.400 \mathrm{~mm}$, concentrados de outubro a março. A temperatura média anual é de $22^{\circ} \mathrm{C}$, com os meses mais quentes cocorrendo de outubro a março (verão) e os mais frios de abril a setembro (inverno), caracterizando o clima como Tropical Sub-úmido com duas estações bem definidas (PORTILHO, 2003). 


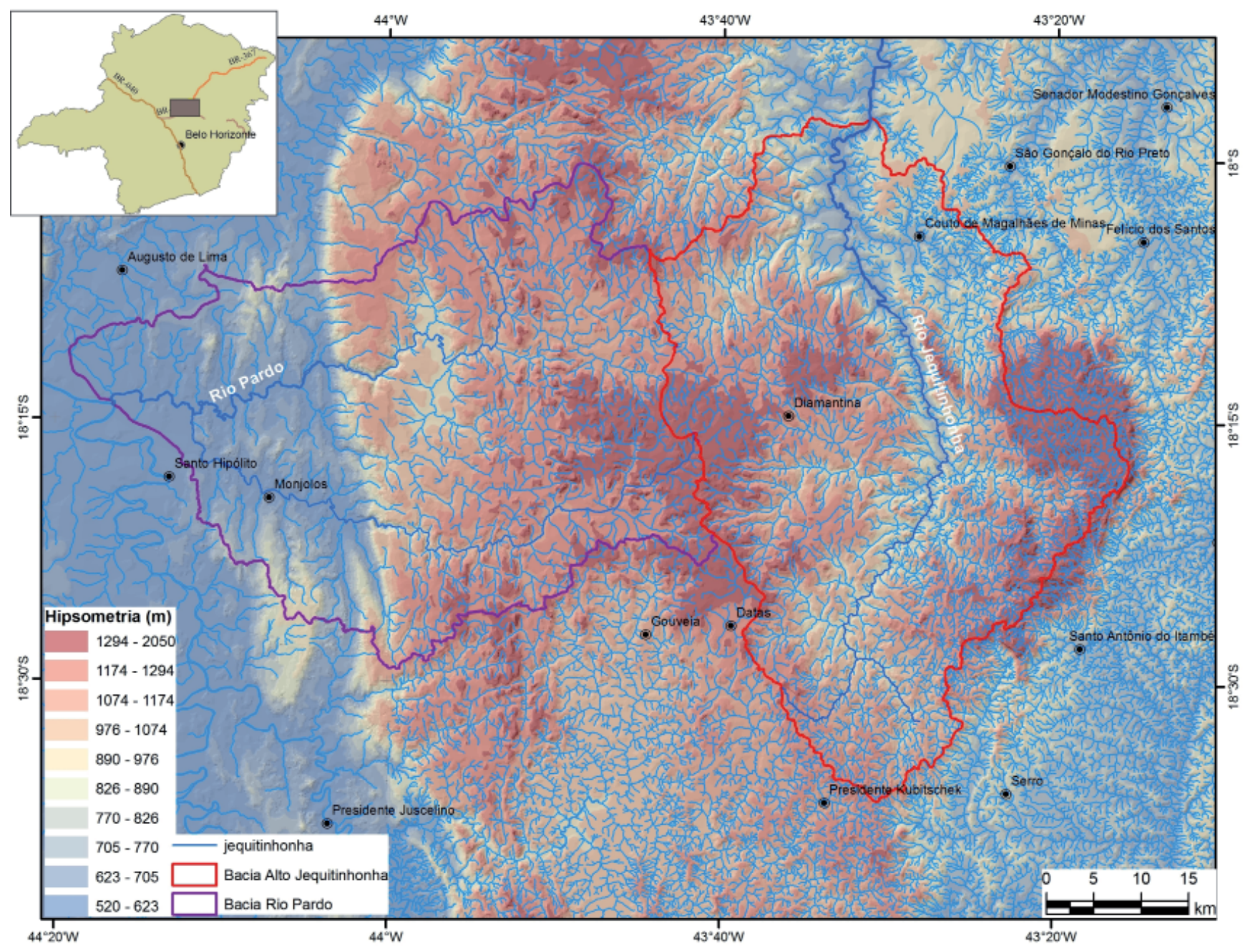

Figura 1 -Localização da área de estudo na Serra do Espinhaço Meridional.

A cobertura vegetal varia de cerrado e cerradão a cerrado degradado, predominantes sobre terrenos graníticos, de xistos, e intrusões de rochas metabásicas e básicas. Nas porções mais elevadas, no domínio dos quartzitos e filitos, alterados predomina a vegetação de altitude, enquanto nos afloramentos de quartzitos, os Campos Rupestres. Ao longo dos rios, se observa a presença de vegetação mais densa, formada por árvores, características de mata ciliar (AUGUSTIN, 1995).

\section{Materiais e métodos}

Levando em consideração a quantidade significativa de erros topológicos presentes nas sete cartas topográficas digitalizadas pelo Projeto Geominas (Figura 2), entre os quais traçados dos rios, foi necessário proceder à correção dos mesmos.
Este não constitui um problema específico da base do Projeto Geominas. Trabalhos entre os quais o de Morisawa (1981), Coffman et. al. (1972) e Dietrich e Dunne (1993), Sampaio (2008), Sampaio e Augustin (2008), Sampaio e Augustin (2014) chamam a atenção para a imprecisão na obtenção de parâmetros morfométricos, em função de equívocos no traçado incorreto da rede de drenagem, bem como na quantificação e localização dos canais de primeira ordem e nascentes em bases cartográficas.

A correção topológica foi executada em procedimento semiautomático através da ferramenta de edição vetorial presente no programa ArcGIS 9.2, contando também com sua extensão Network Analyst.

Para a análise morfométrica, foram considerados os seguintes parâmetros: 


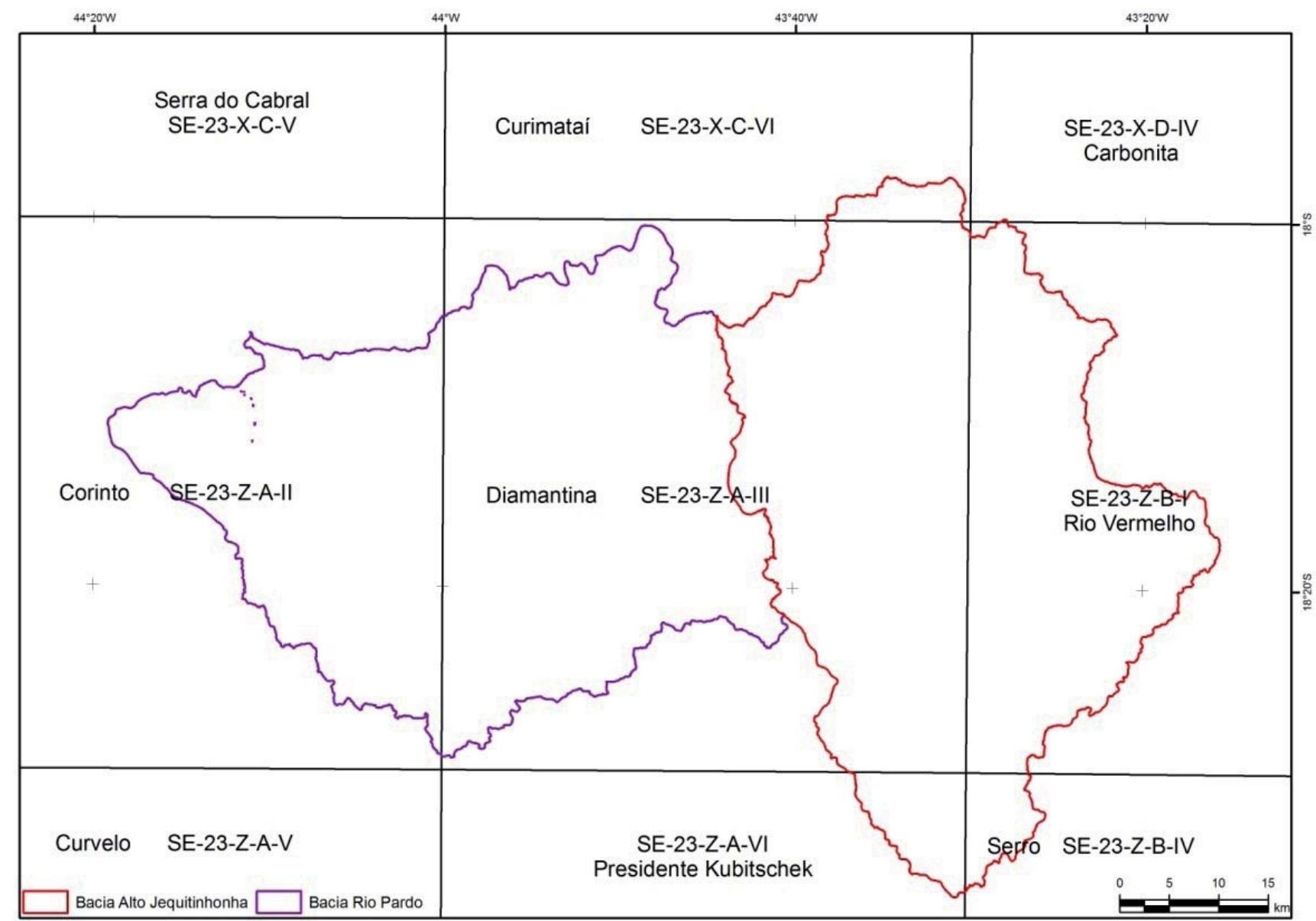

Figura 2 - Limite das cartas topográficas, para a área pesquisada, de acordo com o índice do mapeamento sistemático brasileiro.

\section{Parâmetros Morfométricos}

Todos os parâmetros morfométricos foram calculados em ambiente ArcGIS 9.2, conforme os procedimentos detalhados em Fonseca (2010).

O primeiro deles, a Relação de Bifurcação $(\boldsymbol{R} \boldsymbol{b})$ foi proposto como representação da razão entre o número total de canais de certa ordem, e o número total de canais de ordem imediatamente superior, cujos valores, dentro de uma mesma bacia, devem ser constantes e jamais inferiores a 2 (HORTON, 1945; STRAHLER, 1952a, b). Para Horton, este índice encontra-se relacionado ao relevo e à sua dissecação. Strahler, por sua vez, chama a atenção para o fato de que, apesar desse parâmetro ser altamente estável, ele varia com o controle estrutural, motivo pelo qual sua interpretação é utilizada para inferências sobre este tipo do relevo. De acordo com Pareta e Pareta (2012), valores baixos de Rb são característicos de bacias que foram submetidas a pouco distúrbio estrutural (Strahler, 1964), indicando que o padrão de drenagem não foi alterado por causas estruturais.

A equação que descreve Rb é dada por:

$$
R b=\frac{N w}{N w+1}
$$

onde: $\mathrm{N}_{\mathrm{w}}$ é o número total de canais de determinada ordem; e $\mathrm{N}_{\mathrm{w}+1}$ corresponde ao número total de canais de ordem imediatamente superior.

Outro parâmetro analisado foi o Índice Circularidade (IC). De acordo com Alves e Castro (2003), ele indica que bacias mais alongadas (com índice abaixo de 0,51 ) favorecem o escoamento, e que bacias com tendência a circulares (com valores acima de 0,51), têm escoamento reduzido e alta probabilidade de cheias. $\mathrm{O}$ parâmetro representa também a transmissividade do escoamento superficial concentrado, isto é, se o tempo 
de concentração da bacia é lento ou rápido. Esses são índices importantes que, em conjunto com o Coeficiente de Compacidade, podem fornecer informações significativas sobre probabilidades de enchentes, possibilitando, ainda inferir sobre o potencial erosivo da bacia.

$\mathrm{O}$ valor de IC correlaciona um valor ideal a um mensurado e é dado pela seguinte fórmula (CHRISTOFOLETTI, 1980):

$$
I C=\frac{12.57 A}{p^{2}}
$$

Onde: $\boldsymbol{A}$ é a área da bacia analisada e $P^{2}$, o perímetro da bacia. Quanto mais próximo ele for de 1, mais circular será a bacia hidrográfica, sendo que este índice nunca é maior do que 1 .

O Coeficiente de Compacidade $(\boldsymbol{C C})$ relaciona a forma da bacia a um círculo. Constitui a relação entre o perímetro da bacia e a circunferência de um círculo de área igual ao da bacia (CARDOSO et al., 2006). Esse coeficiente é um número adimensional que varia com a forma da bacia independentemente de seu tamanho. Quanto mais irregular for a bacia, maior será seu coeficiente de compacidade. De acordo com Christofoletti (1980), esse valor deve ser maior ou igual a 1 e foi calculado pela fórmula:

$$
C C=\frac{0.2821 P}{A^{0.5}}
$$

Onde: $P$ é o perímetro da bacia e A é a área da bacia. De acordo com Zavoianu (1985), existe uma relação de proporcionalidade direta entre o aumento da área de drenagem das sucessivas ordens de canais e o perímetro da bacia. Assim, o perímetro tende a aumentar, na medida em que há um número maior de canais, o que, por sua vez, está ligado a fatores geológicos, geomorfológicos e climáticos.

O parâmetro Densidade de Drenagem $(\boldsymbol{D d})$ reflete a distância espacial entre os canais de uma determinada área através da análise da relação entre o comprimento total dos canais de uma bacia com sua área. Valores elevados da densidade da drenagem são indicativos indiretos do grau também mais elevado de dissecação do relevo, decorrentes de fatores tais como declividade, a presença de material subsuperficial pouco permeável, baixa densidade da cobertura vegetal, além de fatores climáticos, entre outros.

Ele é calculado de acordo com a seguinte equação (CHRISTOFOLETTI, 1980):

$$
D d=\frac{L t}{A^{0.5}}
$$

Onde: $L_{t}$ representa o somatório da extensão de todos os rios de uma bacia e $A$ corresponde à área da bacia.

Assim, quando aplicado às bacias hidrográficas em um mesmo ambiente climático, como no caso desta pesquisa, este índice é capaz de expressar a existência de comportamento hidrológico definido pela litologia e estrutura geológica, indicando a capacidade de infiltração e de formação de canais superficiais (CHRISTOFOLETTI, 1970).

Também a Densidade de Rios (Dr), dada pela razão entre o número de rios ou cursos de água e a área drenada pela bacia hidrográfica, foi utilizado. Este índice encontra-se diretamente associado ao índice anterior $(D d)$, pois depende do aumento do número de canais. Significa aumento/diminuição no número de rios, o que pode ser atribuída às mesmas razões apontadas para o índice anterior, e pode indicar maior ou menor dissecação da bacia. Valores baixos podem significar que a densidade dos rios não representa elementos importantes na dissecação do relevo, tratando-se bacia na qual o material erodido tende a ficar retido na própria bacia. Ela foi primeiramente definida por Horton (1945), de acordo com a fórmula:

$$
\operatorname{Dr}=\frac{N}{A}
$$

Onde: $N$ representa o número total de rios ou cursos d’água e $A$, a área da bacia hidrográfica.

Quando as relações topológicas entre os canais de uma bacia estão de acordo com o sistema de hierarquização proposto por Horton, o número de rios corresponde à soma de todos os segmentos de cada ordem, haja vista que esta estabelece uma mesma hierarquia para o canal da nascente até a foz, com exceção dos canais de primeira ordem. Já para a classificação de Strahler, o número de rios corresponde à quantidade de canais de primeira ordem, uma vez que todo rio possui o seu 
segmento de primeira ordem nesta classificação.

O Coeficiente de Manutenção (Cm) foi proposto por Schumm (1956) e considerado um dos mais importantes para caracterização dos sistemas de drenagem (CHRISTOFOLETTI, 1980). Ele indica, indiretamente, a capacidade de uma bacia em geral fluxo constante, promovendo erosão e reafeiçoando o relevo. Corresponde à área necessária para a formação de um canal com fluxo perene, e dado pela equação:

$$
C m=\frac{1}{D d} \times 1.000
$$

Onde: $C m$ é o coeficiente de manutenção e $D d$ é a densidade de drenagem.

O Índice de Concentração de Rugosidade $(\boldsymbol{C r})$, de acordo com Sampaio e Augustin (2008), é calculado através da técnica geoestatística "estimador de densidade por Kernel”, e adota como referencial de análise, a distribuição espacial (dispersão/concentração) da declividade, conforme detalhado em Sampaio (2008), Fonseca (2012) e em Sampaio e Augustin (2008, 2014). Faz uso dos valores indiretos da rugosidade, conforme proposto por Hobson (1972) bem como do entalhamento do relevo (ROSS, 1992), a partir da análise da repetição dos valores de declividade por unidade de área. Esse índice assinala a eficiência do entalhe da drenagem e sua capacidade erosiva na elaboração do relevo na bacia.

\section{Mapeamento de Lineamentos}

A definição de lineamentos incorporada no presente artigo segue o conceito de O'Leary et. al. (1976), que os consideraram como qualquer feição linear, mapeável da superfície, com provável estruturação sub-superficial.

A análise estrutural do relevo teve como base a vasta literatura existente sobre a geologia estrutural da SdEM, além dos dados do Projeto Espinhaço (COMIG, 1996). Foi também necessário realizar a extração de lineamentos estruturais sobre as bandas 4 e 5 do sensor TM/Landsat 5 órbitas/ponto 218/072 e 218/073 das datas 04/2005 e 05/2005 respectivamente, sobre o Modelo Digital de Elevação SRTM (Shuttle Radar Topography Mission), conforme proposto por Liu (1987) e Andrades-Filho e Fonseca (2009). Neste procedimento, foram utilizadas as técnicas de Processamento Digital de Imagens, tais como os de filtros direcionais nas bandas 4 e 5, tendo como base procedimentos detalhados em Centeno (2003), e Amaro e Strieder (1994).

O tratamento estatístico dos lineamentos (frequência absoluta, comprimento médio e comprimento absoluto) foi realizado no programa SPRING/INPE e apresentado graficamente através de Diagrama de Roseta.

A análise de lineamentos foi acompanhada por controles de campo para identificação in loco das principais feições assinaladas e identificadas durante as fases de PDI. Foram, ainda, utilizadas cartas topográficas digitalizadas do IBGE (1978), na escala 1:100.000. Todos os mapas e demais cálculos morfométricos foram realizados no ArcGIS 9.3.1.

\section{Resultados e discussão}

\section{Parâmetros morfométricos}

As bacias hidrográficas do rio Pardo e Alto Jequitinhonha possuem eixos principais de drenagem dispostos de forma quase ortogonal, uma vez que seus rios principais apresentam direção de fluxo basicamente E-W e S-N respectivamente (Figura 3). Suas dimensões areais e formas são muito semelhantes, apresentando índices de circularidade que indicam forte tendência ao alongamento (Tabela 1), sendo o Pardo no sentido L-W e o Jequitinhonha no sentido S-N. O rio principal de cada bacia reforça a semelhança entre as mesmas, pois apresentam a mesma ordem fluvial (Figura 3).

A configuração espacial da rede de drenagem em relação às áreas das bacias analisadas pode ser verificada através da densidade de drenagem e de rios, apresentada na Tabela 2. De acordo com ela, a bacia do rio Pardo possui os menores valores de densidade de rios e de segmentos da rede de drenagem. Já a bacia do Alto Jequitinhonha, apresenta uma rede de drenagem mais densa, evidenciando a atuação de processos fluviais mais intensos.

O Coeficiente de Manutenção $(\mathrm{Cm})$ indica que a bacia do rio Pardo necessita de uma área mínima maior para a manutenção de um metro de canal de escoamento, do que a bacia do Jequitinhonha (Tabela 2). $\mathrm{O}$ valor de $1106,79 \mathrm{~m}$ /2m significa que, de uma maneira geral, esta 


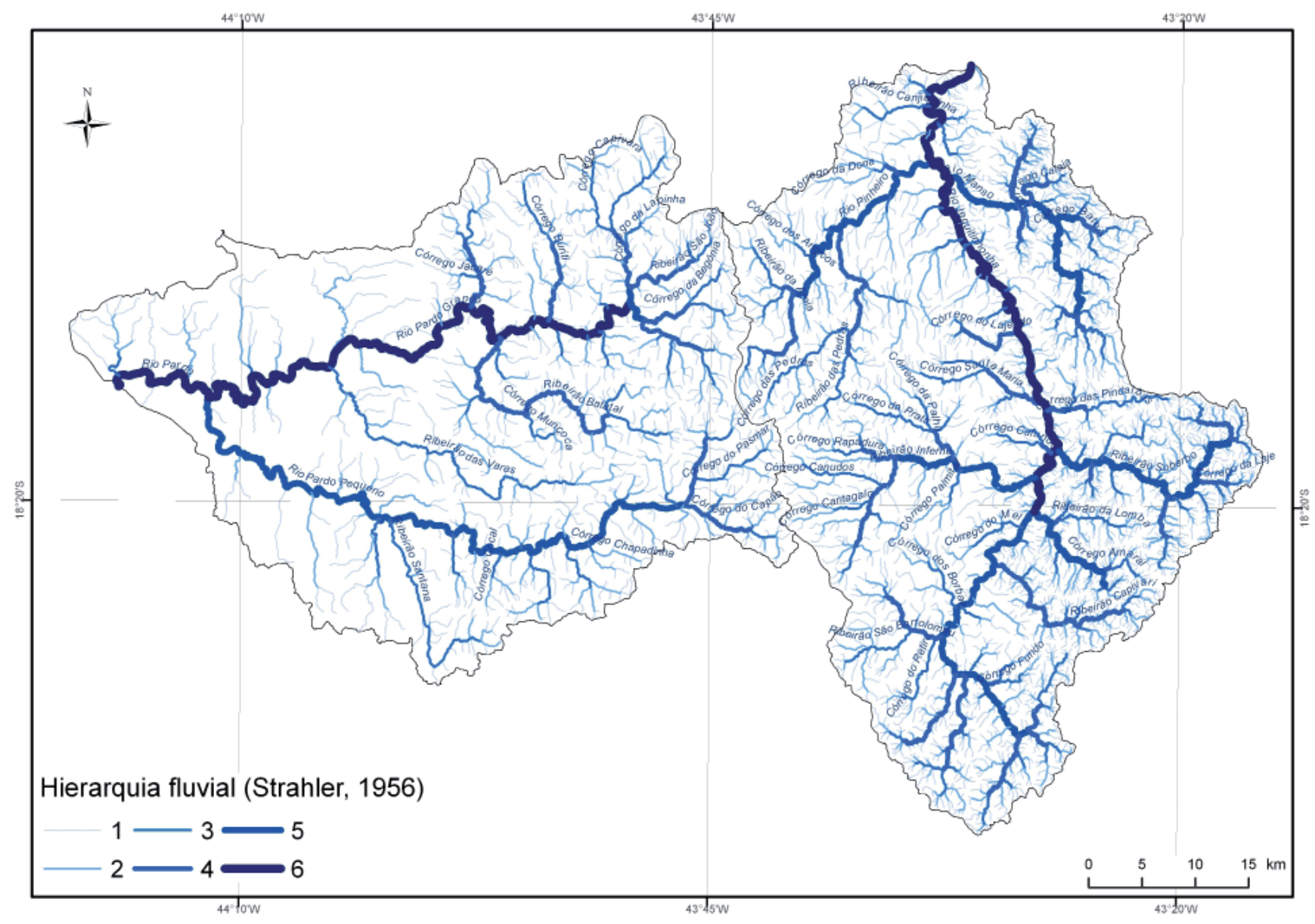

Figura 3 - Hierarquia da rede de drenagem, segundo Strahler (1952a), das bacias do rio Pardo à esquerda, e Alto Jequitinhonha à direita.

Tabela 1 - Parâmetros morfométricos referentes às dimensões e forma das bacias.

\begin{tabular}{|l|r|r|r|r|}
\hline Bacia & Área $\left.\mathbf{( k m}^{2}\right)$ & \multicolumn{1}{|l|}{$\begin{array}{l}\text { Perímetro } \\
\mathbf{( k m )}\end{array}$} & \multicolumn{1}{l|}{$\begin{array}{l}\text { Índice de } \\
\text { Circularidade }\end{array}$} & $\begin{array}{l}\text { Comprimento } \\
\mathbf{( k m )}\end{array}$ \\
\hline Rio Pardo & 2028,7552 & 262,6879 & 0,3696 & 66,9227 \\
\hline $\begin{array}{l}\text { Alto } \\
\text { Jequitinhonha }\end{array}$ & 2053,7594 & 251,3500 & 0,4086 & 71,6117 \\
\hline
\end{tabular}

Tabela 2 - Parâmetros morfométricos referentes à relação rede de drenagem/área da bacia.

\begin{tabular}{|l|rr|l|lr|}
\hline Rio & \multicolumn{2}{|l|}{$\begin{array}{l}\text { DR } \\
\text { Densidade de } \\
\text { Rios }\end{array}$} & $\begin{array}{l}\text { DD } \\
\text { Densidade de } \\
\text { Drenagem }\end{array}$ & $\begin{array}{l}\text { Cm } \\
\text { Coeficiente de } \\
\text { Manutenção. }\end{array}$ \\
\hline Pardo & 0,37 & 0,90 & 1106,79 \\
\hline Alto Jequitinhonha & 1,09 & 1,57 & 635,84 \\
\hline
\end{tabular}


bacia tem um menor número de cursos de água do que a bacia do Alto Jequitinhonha, que é bem mais drenada, necessitando de $635,8 \mathrm{~m}^{2}$ para a manutenção de 1 metro de rio. Isto pode estar relacionado ao fato de que parte da drenagem do Rio Pardo é subterrânea, por causa da presença do calcário, o que explicaria o menor número de cursos de água identificados.

Tabela 3 - Parâmetros morfométricos referentes à relação rede de drenagem/área da bacia.

\begin{tabular}{|l|r|r|r|r|r|r|}
\hline Rio & Rb_1_2 & Rb_2_3 & Rb_3_4 & Rb_4_5 & Rb_5_6 & \multicolumn{1}{l|}{ Rbm } \\
\hline Pardo & 1,98 & 2,02 & 2,20 & 1,63 & 1,16 & 1,80 \\
\hline $\begin{array}{l}\text { Alto } \\
\text { Jequitinhonha }\end{array}$ & 1,98 & 2,08 & 2,22 & 1,07 & 2,74 & 2,02 \\
\hline
\end{tabular}

Rb_1_2: Relação de Bifurcação, entre segmentos de drenagem das respectivas hierarquias.

Rbm: Relação de Bifurcação média.

A Tabela 3 mostra que os valores da Relação de Bifurcação (Rb) para os segmentos da bacia do rio Pardo não apresentam um padrão específico. É possível observar que, a partir da quarta ordem fluvial, há uma relação inversa no que se refere à $\mathrm{Rb}$ e as ordens hierárquicas, ou seja, quanto menor a ordem hierárquica, maior a relação de bifurcação.

Este fato aparentemente justifica a grande quantidade de segmentos de alta hierarquia fluvial e a pequena quantidade de segmentos de baixa hierarquia fluvial, em termos relativos quando comparado com a bacia do Alto Jequitinhonha (Figura 3). Nesta, o mesmo parâmetro indica um maior número de segmentos de terceira ordem em relação à de quarta, e de quinta ordem em relação à de sexta (Figura 3). O valor similar da relação de bifurcação dos canais de primeira e segunda ordem nas duas bacias aponta para o fato de que parece ocorrer certa estabilidade nas zonas de cabeceiras (Tabela 3).

No entanto, ao analisar a relação de $\mathrm{Rb}$ para as ordens hierárquicas superiores (exceto a 4 a ordem), o Alto Jequitinhonha apresenta um número maior de canais de ordem inferiores, espelhando sua baixa capacidade de articular canais formadores de sub-bacias maiores (Tabela 3). Este fato pode ser interpretado como resultante de maior atividade de energia nesta bacia, o que dificulta o desenvolvimento de canais mais complexos, de ordens superiores (FONSECA e AUGUSTIN, 2011).

A análise da rede de drenagem também pode ser utilizada como um indicador da evolução do relevo. Segundo Summerfield (1991), padrões de drenagem podem apontar controle tectônico, e através de seu re- conhecimento seria possível compreender e classificar estruturas geológicas regionais. $\mathrm{O}$ autor faz distinções entre controles tectônicos passivos, que se dão pelo controle de estruturas geradas por tectônica previamente ativa com relação à instalação da drenagem e controle tectônico ativo, quando a rede de drenagem é controlada por lineamentos ativos contemporâneos à instalação das bacias hidrográficas.

Nesse sentido, Augustin (1995) propôs a evolução da drenagem das principais bacias do Espinhaço Meridional em quatro grandes fases que possuem correlação direta com a evolução geotectônica e diferenças litoestruturais dessas regiões submetida à deformação. Essa evolução e sua dinâmica podem ser extrapoladas para as duas bacias em análise.

De acordo com a autora, a primeira fase teve como elemento norteador da drenagem os principais eixos de sinclinais e anticlinais resultantes dos dobramentos durante a tectônica Brasiliana, sendo que esta influência estrutural permanece até os dias de hoje, orientando parte da drenagem nas direções N-S/S-N. Através do mapa geológico (Figura 4), é possível observar a relação deste primeiro elemento com um importante sistema de falhas de empurrão/zonas de cisalhamento com direção geral N-S, contendo amplas dobras de eixo que tendem para N-S, abertas e com vergência para W (FOGAÇA e SCHÖLL, 1984), representando evento deformacional principal, o Evento Brasiliano (UHLEIN, 1991).

A segunda fase proposta por Augustin (1995) encontra-se condicionada pelas falhas transcorrentes, fraturas e juntas nas direções E-W/W-E (Figura 4), 


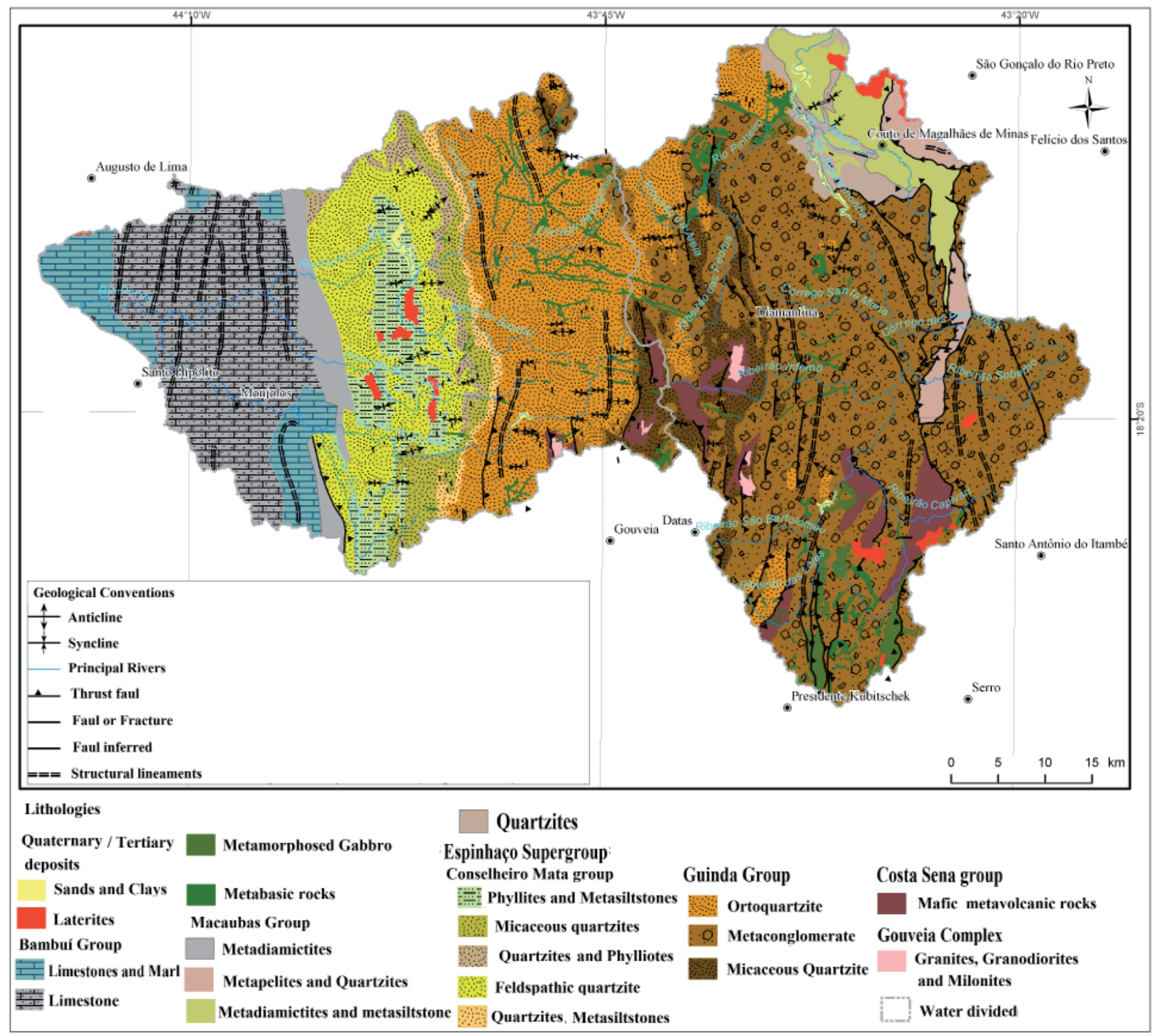

Figura 4 - Mapa Geológico simplificado (Fonte: COMIG, 1996).

que comandam parte da rede de drenagem, geralmente destrais, como pode ser observado nos lineamentos morfoestruturais (Figura 5).

A terceira fase da dinâmica de encaixamento da drenagem foi realizada predominantemente ao longo das intrusões lineares (diques e sills) de rochas metabásicas tardi-tectônicas do Evento Brasiliano na área Espinhaço, e básicas pós Brasiliano, cuja menor resistência ao intemperismo, segundo a autora (op.cit.), é aproveitada para a incisão da drenagem (Figuras 4 e 5).

E, finalmente, no Quaternário, a ampliação da rede de drenagem se processa com a abertura e o aprofundamento de erosão linear acelerada, em especial voçorocas que, após atingir o nível freático, passam a contribuir diretamente com água e sedimentos para os cursos fluviais (AUGUSTIN, 1995; AUGUSTIN e ARANHA, 2006). Este último ciclo está relacionado às morfologias associadas ao complexo Gouveia, fora da área de estudo da presente pesquisa.

A distribuição espacial de três fases evolutivas para a área pesquisada pode ser observada na figura 6 .

\section{Análise dos Lineamentos}

Os filtros direcionais aplicados nas bandas 4 e 5 do sensor TM Landsat 5 extraído do MDE, permitiram 


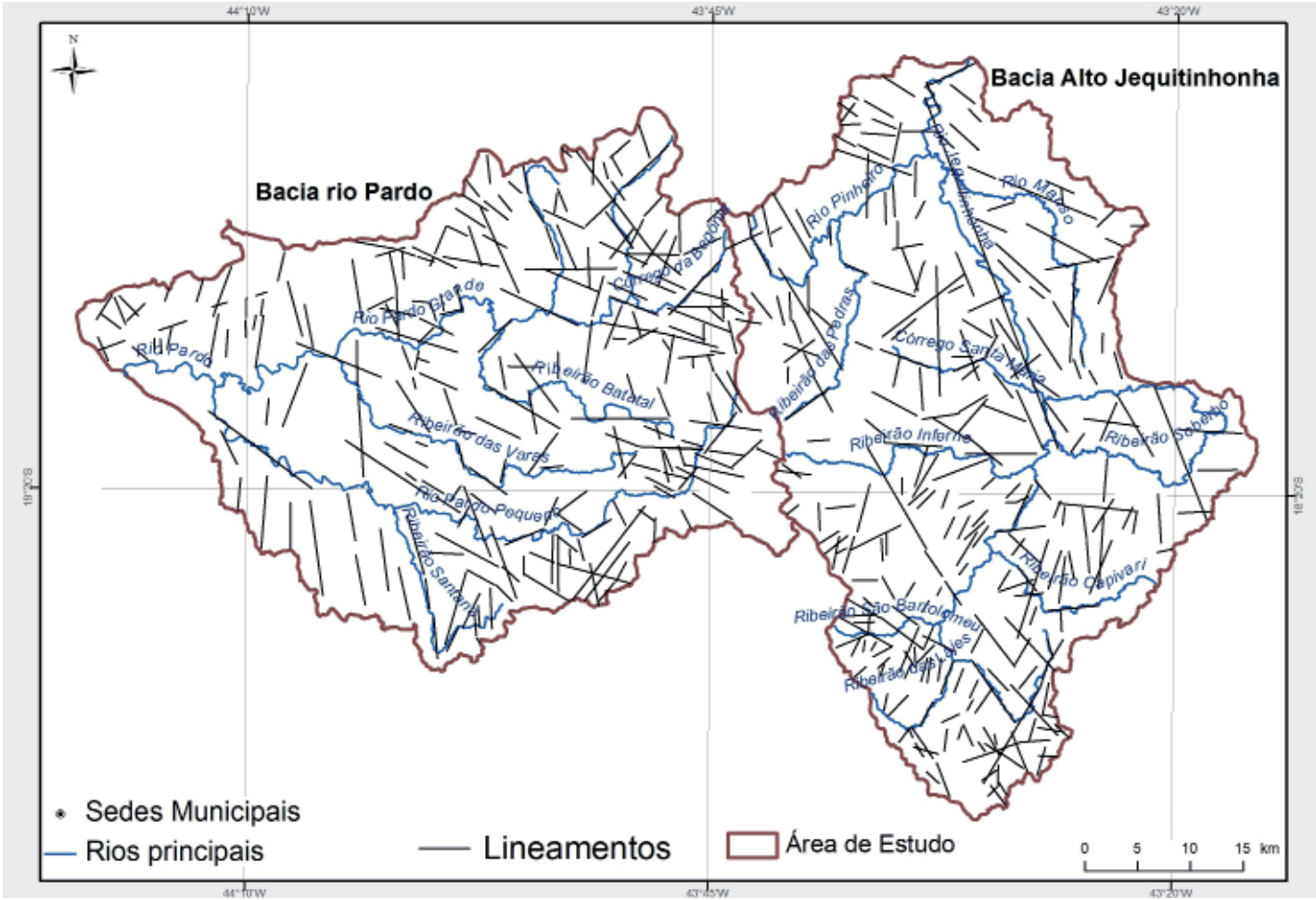

Figura 5 - Lineamentos morfoestruturais das bacias dos rios Pardo e Alto Jequitinhonha extraídos do MDT e das imagens de landsat.

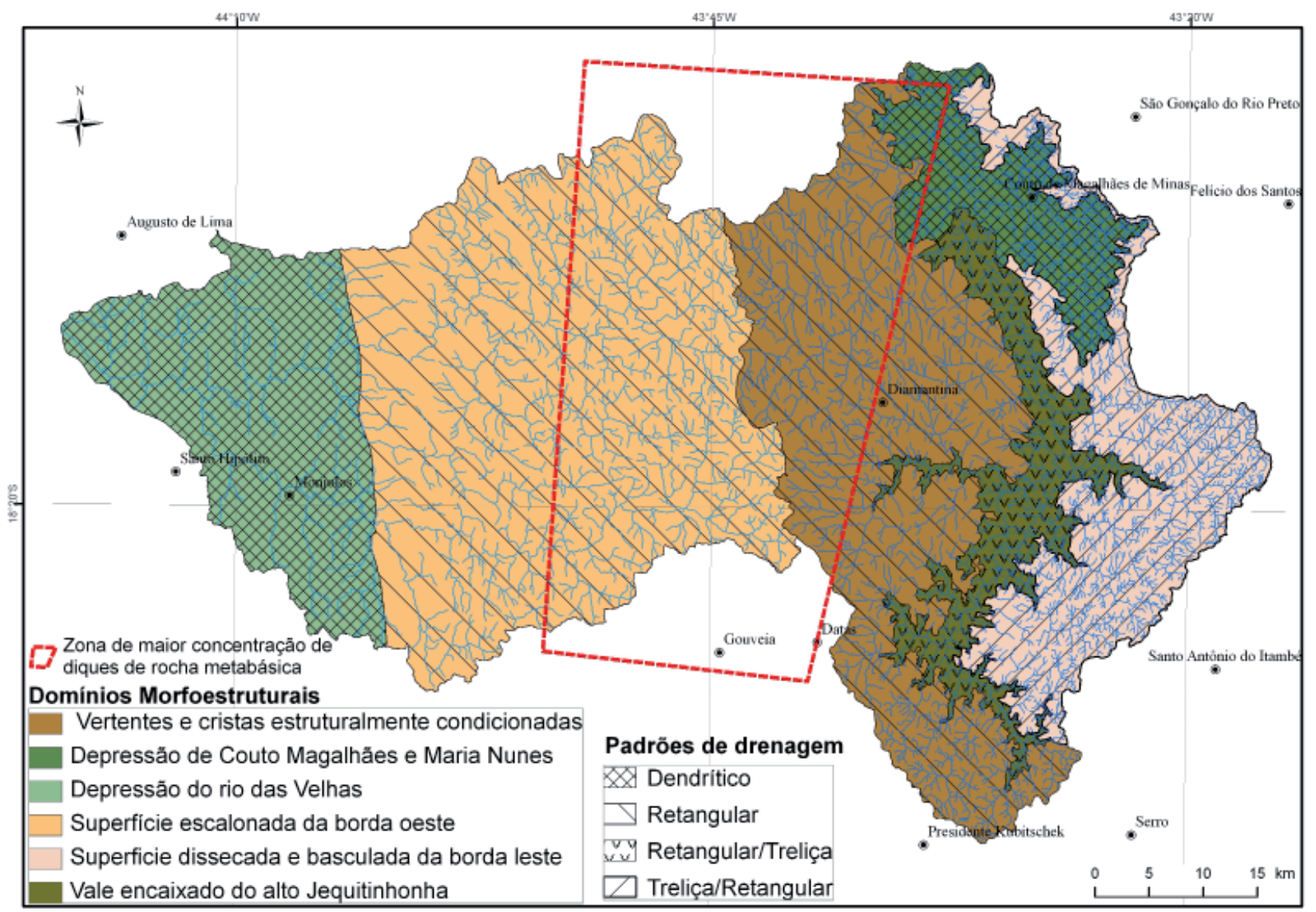

Figura 6 - Domínios morfoestruturais e padrões de drenagem para as bacias do rio Pardo, à esquerda, e alto Jequitinhonha à direita. Na porção central observa-se a zona de adensamento de diques de rochas metabásicas. 
a identificação de 240 lineamentos na bacia do rio Pardo Grande e 265 lineamentos na bacia do Alto Jequitinhonha (Figura 5), indicando que não há diferença numérica muito grande entre as duas bacias estudadas.

Os lineamentos de maior extensão, no entanto, estão presentes na bacia do Alto Jequitinhonha, sendo que o maior lineamento possui 35,52 km de extensão (Figura 5). Já na bacia do rio Pardo os maiores lineamento não ultrapassaram 12,17 km de extensão, conforme ilustrado na Figura 5. Este é um fator que pode ser importante na determinação dos processos de infiltração da água de chuva, reabastecimento dos níveis freáticos e naqueles relacionados ao intemperismo das rochas em profundidade e que podem estar afetando as taxas erosivas das duas bacias.

Comparando o mapa de domínios morfoestruturais (Figura 6) com o mapa geológico (Figura 4), é possível observar que os padrões de drenagem em treliça e retangular estão associados à ocorrência de um grande pacote quartzítico do Supergrupo Espinhaço. Já o padrão dendrítico na bacia do Alto Jequitinhonha associa-se, localmente, à presença de metapelitos e metadiamictitos do Grupo Macaúbas (Figura 4).

Na bacia do rio Pardo, este padrão está vinculado à presença de rochas sedimentares carbonáticas do Grupo Bambuí (Figuras 4 e 6). Esse padrão de drenagem tende a desenvolver-se em regiões de rochas de resistência uniforme, ou em estruturas sedimentares horizontalizadas (GREGORY e WALLING, 1983). É possível observar ainda, que o padrão dendrítico possui uma distribuição espacial concentrada em zonas de agradação, nas quais as rochas apresentam menor resistência à incisão da drenagem comparada às áreas de degradação (Figura 4).

\section{Principais Direções dos segmentos da drenagem}

Com o objetivo de identificar as direções principais de segmentos de drenagem, foram construídos diagramas de rosetas (Figura 7) para cada domínio morfoestrutural delimitado. Posteriormente, os diagramas foram comparados com as direções principais descritas nos ciclos evolutivos de Augustin (1995).

É importante ressaltar que os domínios morfoestruturais representados pela Depressão do rio das Velhas, Depressão de Couto Magalhães e Maria Nunes não apresentam litótipos do Supergrupo Espinhaço, mas guardam as marcas estruturais da evolução geotectônica do Espinhaço durante o Brasiliano.

De um modo geral, é possível constatar que todos os domínios morfoestruturais apresentam direções de drenagem que estão associadas à primeira fase evolutiva, proposta por Augustin (1995).

Os diagramas A e C (Figura 7) indicam que os segmentos de drenagem da bacia do rio Pardo, com exceção das drenagens principais (rios Pardo e Pardo Pequeno), são mais frequentes nas direções N-S/S-N e NNW-SSE/NNE-SSW. O diagrama A, por exemplo, que representa o domínio da depressão do rio das Velhas, aponta para um predomínio de direções de drenagem basicamente nos sentidos N-S/S-N. Percebe-se então, a influência de lineamentos estruturais de regime compressional (Figuras 4 e 5) na mesma direção, o que também explica as anomalias representadas pela existência de canais retilíneos e confluências em ângulos retos em um domínio morfoestrutural com padrão de drenagem dendrítico.

A análise visual do Índice de Concentração da Rugosidade - ICR (Figura 8) mostra que a bacia do Alto Jequitinhonha apresenta as maiores concentrações de rugosidade, o que pode ser associado à sua maior dissecação fluvial. É possível perceber também que nesta bacia a distribuição espacial dos cinco classes do índice de concentração da rugosidade é mais equilibrada, ou seja, a maior rugosidade é encontrada em diversos pontos da bacia. Já na bacia do rio Pardo, a rugosidade concentra-se na porção topograficamente mais elevada, localizada na sua porção central que correspondente à escarpa da Borda Oeste do Espinhaço Meridional (AUGUSTIN et al., 2011).

Os lineamentos estruturais (Figura 5) obtidos a partir das cartas geológicas do Projeto Espinhaço (COMIG, 1996) mostram que a área de abrangência do domínio da Borda Oeste Escalonada (Figura 4) concentra a totalidade de falhas transcorrentes (E-W/W-E) e parte considerável das falhas e fraturas com sentido E-W/W-E. Esta configuração estrutural é claramente estabelecida na segunda fase de evolução da rede de drenagem proposta por Augustin (1995).

Já o diagrama C (Figura 7) indica que os segmentos da rede de drenagem com sentido E-W/W-E se tornam mais freqüentes em relação ao diagrama A. Ao 
Análise Morfométrica de Bacias de Drenagem e sua Relação com a Estrutura Geológica, Serra do Espinhaço
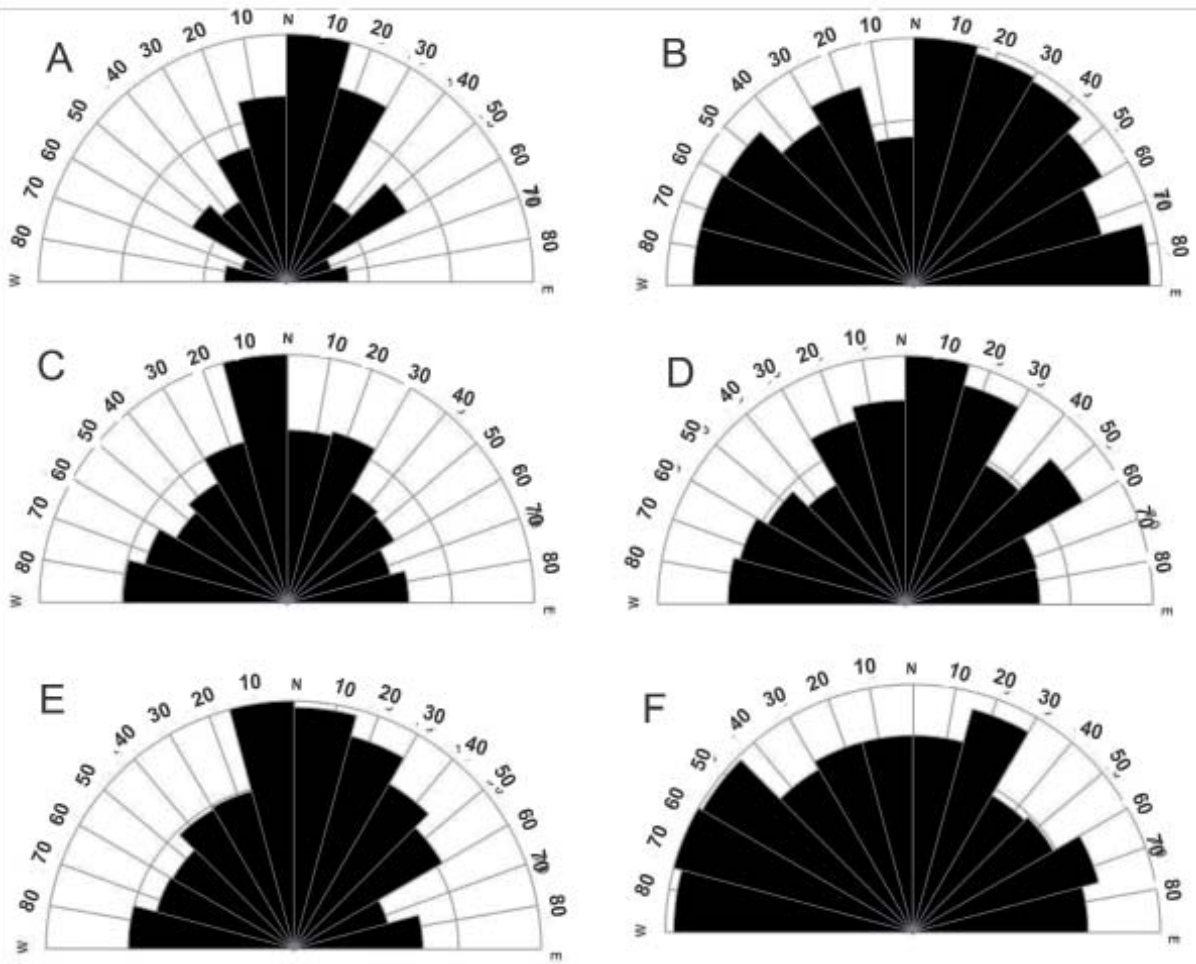

Figura 7 - Freqüência absoluta das direções dos canais de drenagem por domínio morfoestrutural. A) Depressão do rio das Velhas; B) Vale encaixado do alto Jequitinhonha; C) Superfície escalonada da borda oeste; D) Superfície dissecada e basculada da borda leste; E) Vertentes e cristas estruturalmente condicionadas; F) Depressão de Couto Magalhães e Maria Nunes.

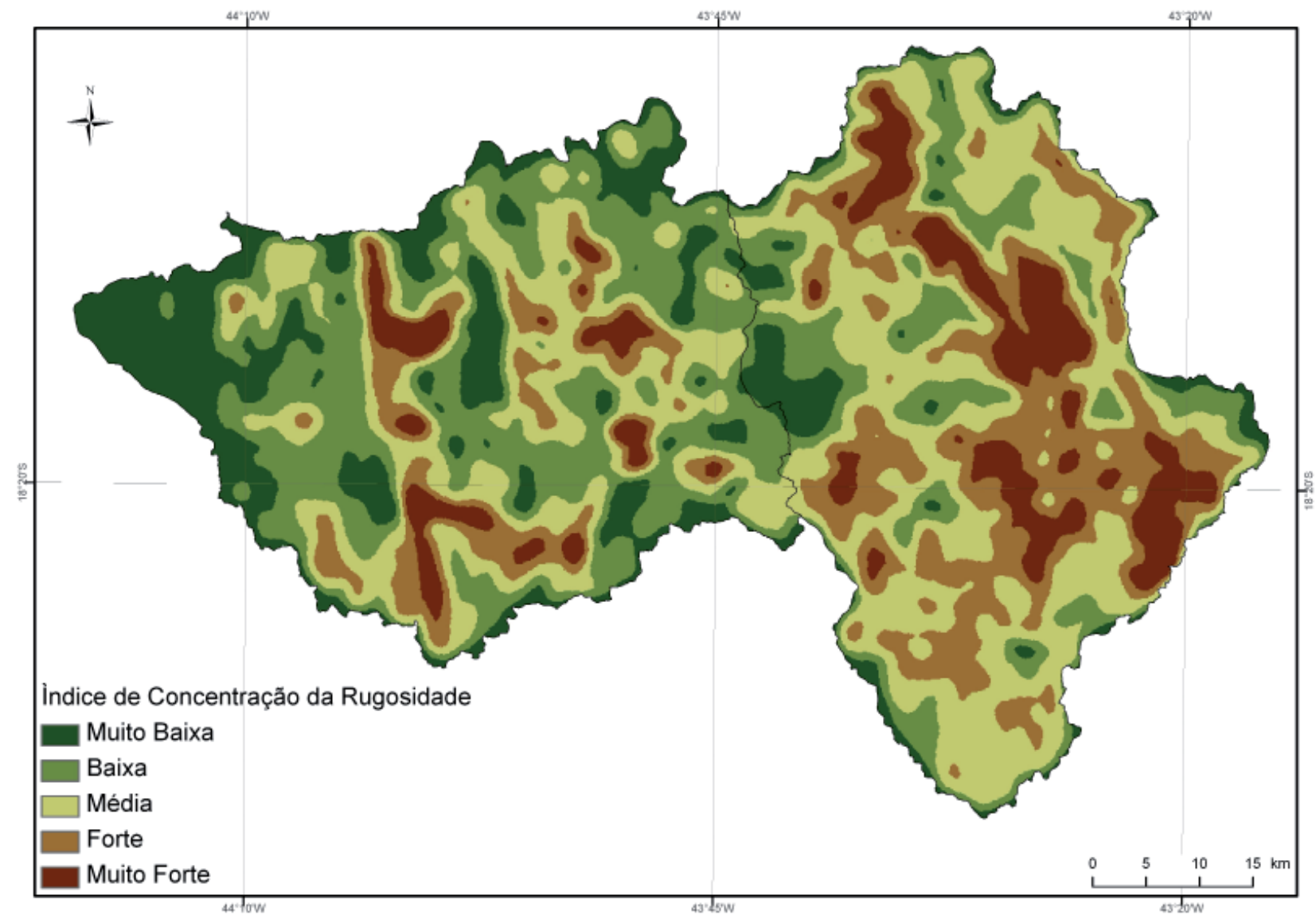

Figura 8 - Índice de concentração da rugosidade nas duas bacias analisadas. 
analisar o diagrama de roseta (Figura 9) do comprimento médio dos canais de drenagem do compartimento morfoestrutural da Borda Oeste Escalonada (Figura 6), percebe-se melhor a distribuição nas direções E-W/W-E e suas respectivas derivações. A pétala acentuada (outlier) na direção $\mathrm{N} 50^{\circ} \mathrm{E}$, sentido $\mathrm{NE}$ - SW realça a presença dos rios Pardo e Pardo Pequeno (maiores comprimentos) os quais seguem no sentido NE-SW até a altura do Distrito de Conselheiro Mata.

A maior concentração espacial dos diques de rocha metabásica que caracteriza a zona de ocorrência da terceira fase de evolução da rede de drenagem proposto por Augustin (1995) pode ser observada na figura 4.

Percebe-se que esta terceira fase não ocorre em um domínio morfoestrutural específico, mas apresenta-se bem distribuído nos compartimentos morfoestruturais da Superfície Escalonada da Borda Oeste e Vertentes e das Cristas Estruturalmente Condicionadas identificados na figura 6.

O cotejamento dos diagramas de rosetas das frequências absolutas de todos os canais de drenagem (Figura 7) com os diagramas de rosetas das frequências

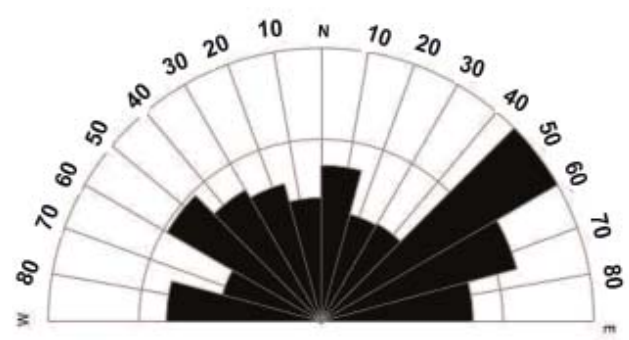

Figura 9 - Diagrama de roseta do comprimento médio dos canais de drenagem do domínio morfoestrutural superfície escalonada da borda oeste.

absolutas dos lineamentos estruturais (Figura 10) permite identificar entre as pétalas representando as maiores frequências, uma correlação geral de uma com a outra.

Isto indica a existência do condicionamento da rede de drenagem aos lineamentos estruturais. Somente os diagramas C e C1 e D e D1, presentes nas figuras 7 e 10, respectivamente, mostram maiores discrepâncias em relação às direções mais freqüentes. Esses diagramas correspondem aos domínios morfoestruturais com maior número de canais de primeira ordem e também
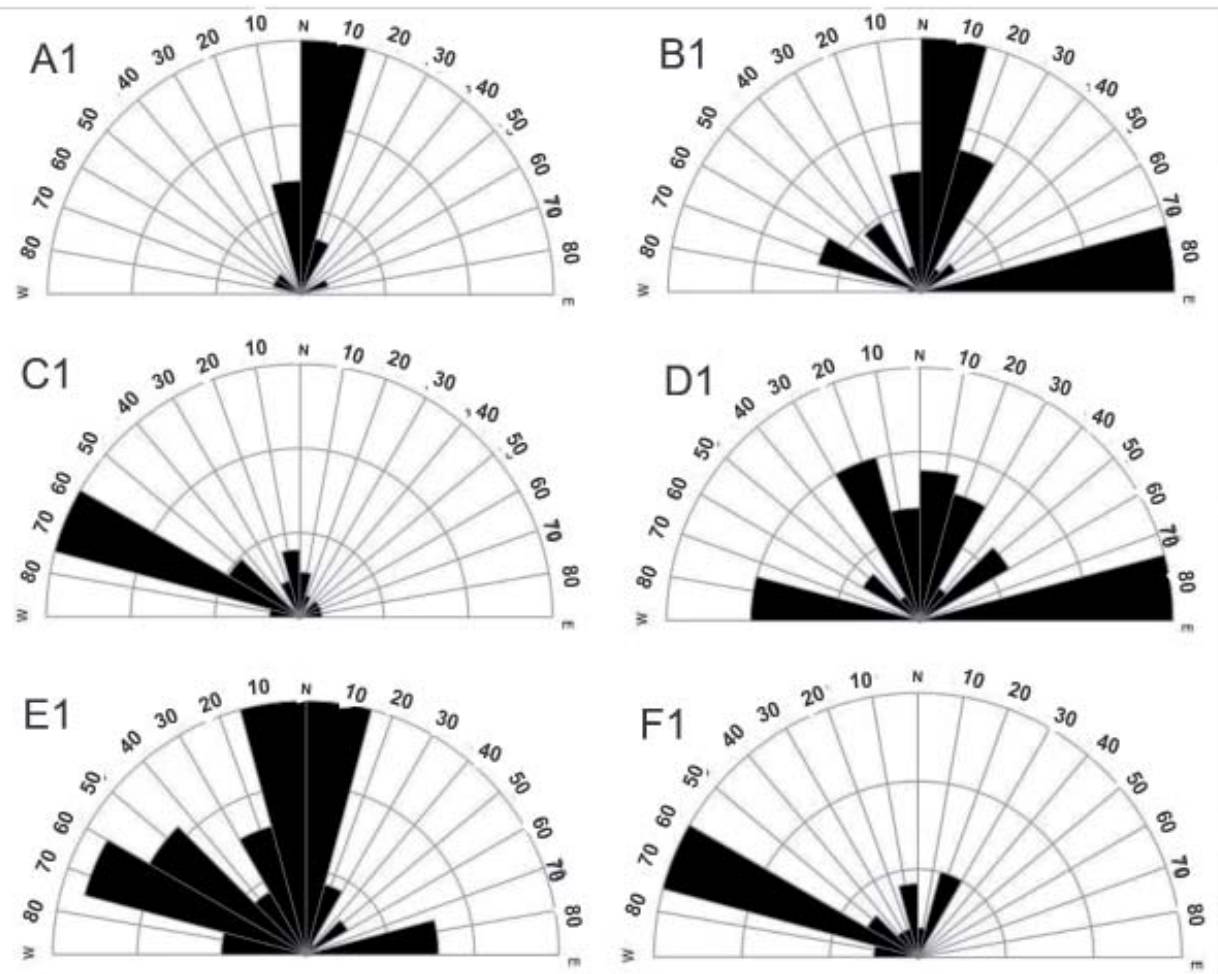

Figura 10 - Freqüência absoluta das direções dos lineamentos estruturais por domínio morfoestrutural: A1) Depressão do rio das Velhas; B1) Vale encaixado do alto Jequitinhonha; C1) Superfície escalonada da borda oeste; D1) Superfície dissecada e basculada da borda leste E1) Vertentes e cristas estruturalmente condicionadas; F1) Depressão de Couto Magalhães e Maria Nunes. 
às áreas topograficamente mais elevadas, tanto da bacia do rio Pardo (C e C1), quanto da bacia do alto Jequitinhonha (D e D1).

As correlações entre lineamentos estruturais e canais de drenagem tornam-se mais evidentes quando os canais de ordens inferiores são extraídos da análise, e são considerados apenas os canais de hierarquia fluvial superior (Figura 3). As direções dos principais rios das bacias analisadas foram comparadas com as direções dos lineamentos estruturais, conforme observado na figura 11. Ao excluir os canais de drenagem de menor ordem fluvial da presente análise, os diagramas de rosetas apresentaram maior correlação entre as direções dos lineamentos estruturais e direções dos rios principais.

Os diagramas de rosetas revelam que a bacia do Alto Jequitinhonha possui uma maior correlação entre as direções dos lineamentos estruturais e dos rios principais, tanto para suas respectivas frequências absolutas, quanto para os comprimentos absolutos. No caso da bacia do rio Pardo, as correlações são menos expressivas ou mesmo inexistentes, indicando que estes lineamentos tem menor influência na drenagem e, consequentemente, na abertura dos vales.

Também o Índice de Relação de Bifurcação mostrou semelhança entre a relação do número de canais de primeira, e segunda ordens em ambas as bacias.
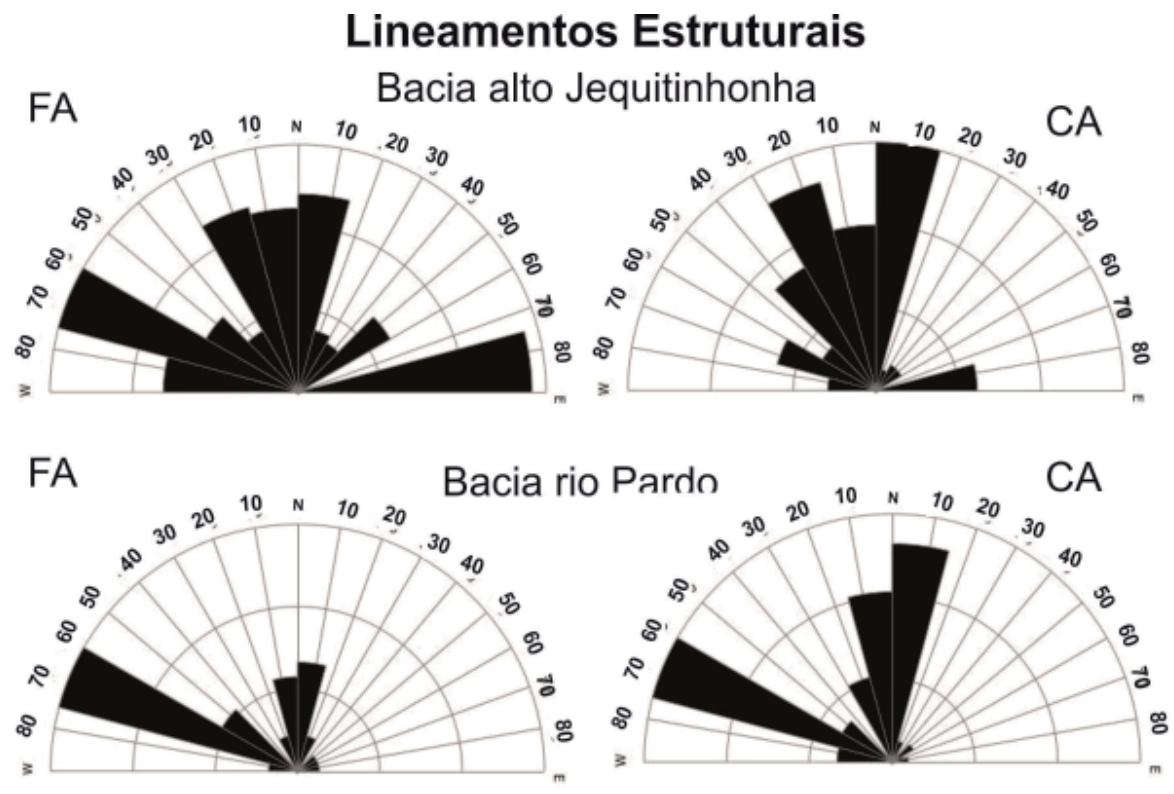

\section{Rios Principais}
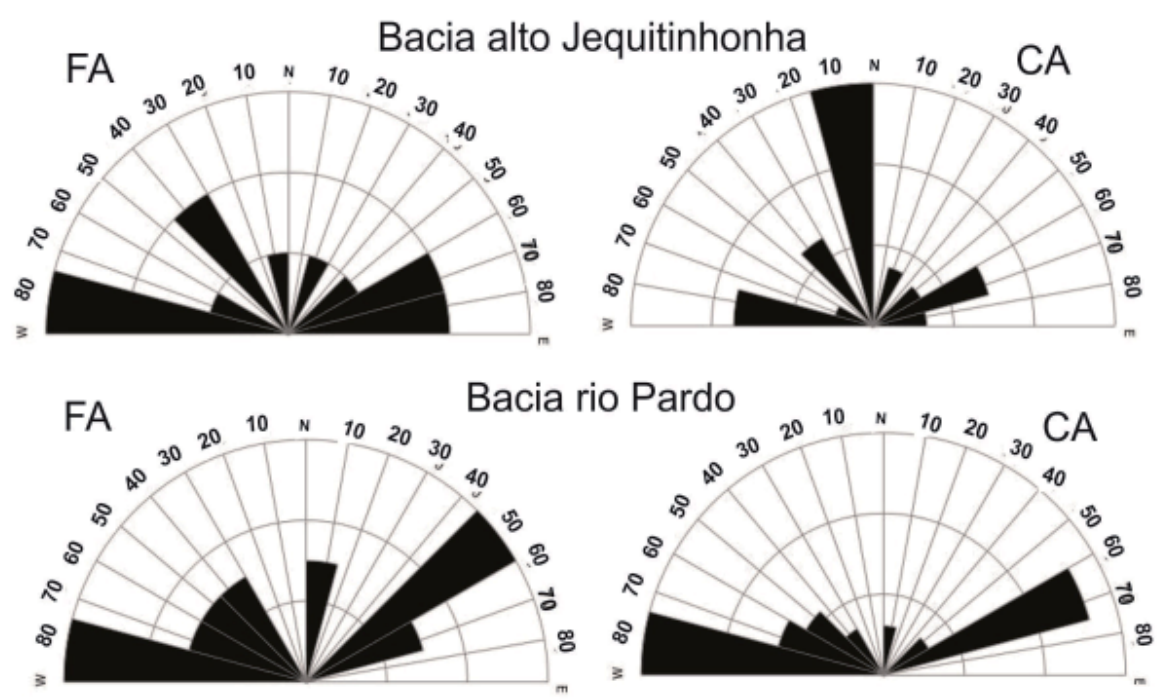

Figura 11 - FA: Freqüência Absoluta e CA: Comprimento Absoluto dos rios principais e lineamentos estruturais. 
Isto se refere basicamente aos canais localizados nas cabeceiras, o que parece indicar um padrão de evolução semelhante nas zonas mais elevadas das duas bacias. No entanto, este índice não traduz o número absoluto de canais. Juntamente com as demais variáveis acima mencionadas, este índice não mostra a existência de diferenças importantes entre as duas bacias. Enquanto a do rio Pardo, conta com um menor número de cursos de água, e, portanto, de um número menor de canais de primeira ordem (748), a bacia do Alto Jequitinhonha, mesmo apresentando um grau hierárquico semelhante à do rio Pardo (6 $6^{\mathrm{a}}$. ordem), possui 2244 canais de primeira ordem, o que corresponde a três vezes mais canais desta ordem (FONSECA, 2010). Essa diferença parece estar associada a uma maior eficiência na formação e desenvolvimento de sub-bacias de drenagem no Alto Jequitinhonha. Este dado, quando comparado com o índice de rugosidade, reflete o fato da bacia do Alto Jequitinhonha apresentar maior grau de dissecação do que o rio Pardo, o que já foi demonstrado por Fonseca e Augustin (2011) através mensuração da energia dos canais de drenagem utilizando o Índice de Hack.

\section{Conclusão}

A rede de drenagem das duas bacias estudadas, a do rio Pardo, na borda oeste do Espinhaço Meridional, e a do Alto Jequitinhonha, na borda leste, demonstram evidências de forte controle exercido pelos elementos litoestruturais herdados da evolução geológica das rochas do Supergrupo Espinhaço, identificado pelos diagramas de roseta, em especial no que se refere às ordens mais altas da hierarquia fluvial. As análises dos lineamentos apontam direções preferenciais da instalação das duas redes de drenagem, que obedeceram, inicialmente, os eixos dos sinclinais e anticlinais, depois as direções das falhas transcorrentes e, posteriormente, às intrusões de rochas metabásicas e básicas, conforme proposto por Augustin (1995).

Dados morfométricos das duas bacias, por outro lado, indicam tratar-se de bacias que apresentam valores semelhantes das variáveis: área, perímetro, índice de circularidade e comprimento. Também o Índice de Relação de Bifurcação mostrou semelhança nas duas bacias entre a relação do número de canais de primeira e segunda ordens correspondentes aos canais localizados nas cabeceiras, o que parece apontar para um padrão de evolução semelhante nas zonas mais elevadas das duas bacias.

No entanto, outros dados indicam a existência de diferenças importantes entre as duas bacias. $\mathrm{O}$ rio Pardo conta com menor número de cursos de água, e, portanto, apresenta um número menor de canais de primeira ordem (748). A bacia do Alto Jequitinhonha, mesmo tendo grau hierárquico semelhante à do rio Pardo (6 $6^{\text {a }}$ ordem), possui 2244 canais de primeira ordem, correspondendo a três vezes mais canais desta ordem (FONSECA, 2010), o que pode estar associado a uma maior eficiência na formação e desenvolvimento de sub-bacias de drenagem. Este dado, quando comparado com o índice de rugosidade, reflete o fato da bacia do Alto Jequitinhonha apresentar maior grau de dissecação do que o rio Pardo.

O Índice de Rugosidade da bacia do Alto Jequitinhonha também é, espacialmente, mais bem distribuído, o que representa uma influência mais homogênea da litologia e estrutura no desenvolvimento da drenagem na borda leste do maciço.

As técnicas de geoprocessamento e processamento digital de imagens associadas às demais abordagem utilizadas indicaram resultados importantes e consistentes, permitindo que fossem estabelecidas relações entre a base geológica das duas bacias estudadas e aspetos e características da evolução das mesmas. Trata-se, portanto, de ferramentas que aplicadas em conjunto com outras técnicas e controle de campo, podem oferecer elementos analíticos substanciais para o entendimento do relevo nas bacias de drenagem a partir de uma abordagem litoestrutural. Dessa maneira, pode-se concluir que a aplicação destes instrumentos analíticos, constitui uma base bastante confiável de comparação dos elementos morfoestruturais das duas bacias.

Ela permite estabelecer associação com a base litoestrutural, e fornece elementos analíticos que possibilitam agilizar o trabalho de campo, além de constituir, em si, um banco de dados e informações para uma interpretação geomorfológica das formas de relevo e dos fatores condicionantes envolvidos na distribuição diferenciada dessas formas.

Agradecimento: À Fundação de Amparo à Pesquisa do Estado de Minas Gerais (FAPEMIG), pelo apoio financeiro a esta pesquisa (CRA APQ 01652-09). 


\section{Referências Bibliográficas}

ALVES, J.M.P.; CASTRO, P.T.A. Influência das feições geológicas na morfologia da bacia do rio do Tanque (MG) baseada no estudo de parâmetros morfométricos e análise de padrões de lineamentos. Revista Brasileira de Geociências vol. 33, n² 2, p. 117-124, 2003.

AMARO, V.E.; STRIEDER, A.J. Análise de Fotolineamentos e Padrões Estruturais em Imagens de Satélite. In: Anais do XXXVII Congresso Brasileiro de Geologia, Camburiú, p. 443-444, 1994.

ANDRADES FILHO, C.O.; FONSECA, L.M.G. Lineamentos Estruturais em imagem Landsat TM e dados SRTM. In: Anais XIV Simpósio Brasileiro de Sensoriamento Remoto, Natal, Brasil, INPE, p. 3151-3158, 2009.

AQUINO, S.; LATRUBESSE, E.M.; SOUZA FILHO, E.E. Caracterização hidrológica e geomorfologia dos afluentes da bacia do Rio Uruguai. Revista Brasileira de Geomorfologia vol. 10, n $\mathrm{n}^{\circ}$ 1, p. 43-54, 2009.

AUGUSTIN, C.H.R.R. Geoökologische Studien im Südlichen Espinhaço Gebirge bei Gouveia, Minas Gerais, Brasilien, Unter Besonderer Berücksichtigung der Landschaftsentwicklung. 1995. 324p. Tese de Doutorado Johannes Wolfgang Goethe Universität, Frankfurt, Alemanha.

AUGUSTIN, C.H.R.R; ARANHA, P.R.A. A ocorrência de voçorocas em Gouveia, MG: características e processos associados. Geonomos vol. 14(1-2), p. 75-86, 2006.

AUGUSTIN, C.H.R.R; FONSECA, B.M.; ROCHA, L.C. Mapeamento geomorfológico da Serra do Espinhaço Meridional: primeira aproximação. Geonomos vol. 19, n.2, p. 50-69, 2011.

BAKER, V.R. Geological fluvial geomorphology. Geological Society of America Bulletin 100, p. 1157-1162, 1988.

BLOOMFIELD, J.P.; BRICKER, S.H.; NEWELL, A.J. Some relationships between lithology, basin form and hydrology: a case study from the Thames basin, UK. Hydrol. Process. 25, p. 2518-2530 (2011) Published online 2 March 2011 in Wiley Online Library (wileyonlinelibrary.com) DOI: 10.1002/ hyp.8024.

BOULTON, S.J.; WHITTAKER, A.C. Quantifying the slip rates, spatial distribution and evolution of active normal faults from geomorphic analysis: field examples from oblique-extensional graben, southern Turkey. Geomorphology 104, p. 299-316, 2009.

CARDOSO, C.A.; DIAS, H.C.T.; SOARES, C.P.B.; MARTINS, S.V. Caracterização morfométrica da bacia hidrográfica do rio
Debossan, Nova Friburgo-RJ. Revista Árvore, Viçosa vol. 30, $\mathrm{n}^{\circ}$ 2, p. 241-248, 2006.

CAMOLEZI, B.A.; FORTES, E.; MANIERI, D.P. Controle estrutural da rede de drenagem com base na correlação de dados morfométricos e morfoestruturais: o caso da bacia do Ribeirão do São Pedro-Paraná. Revista Brasileira de Geomorfologia vol. 13, n 2, p. 201-211, 2012.

CARVALHO, T.M.; LATRUBESSE, E.M. O uso de modelos digitais do terreno (MDT) em análises macrogeomorfológicas: o caso da bacia hidrográfica do Araguaia. Revista Brasileira de Geomorfologia vol.5, nº 1, p. 85-93, 2004.

CENTENO, J.A.S. Sensoriamento remoto e processamento de imagens digitais. Curitiba: Ed. Curso de Pós-Graduação em Ciências Geodésicas, Universidade Federal do Paraná, 2003. $210 \mathrm{p}$.

CHRISTOFOLETTI, A. Análise morfométrica das bacias hidrográficas do Planalto de Poços de Caldas. 1970. $215 f$. Tese de Livre Docência. Faculdade de Filosofia, Universidade Estadual de São Paulo, Rio Claro.

CHRISTOFOLETTI, A. Geomorfologia. São Paulo: Edgard Blücher, 1980. $186 \mathrm{p}$.

COMIG. Projeto Espinhaço. Belo Horizonte, Cia. Mineradora de Minas Gerais, 1996. 1CD-ROM (Incluindo 23 mapas geológicos, esc.1:100.000).

DEFFONTAINES, B.; CHOROWICZ, J. Principles of drainage basin analysis from multisource data: application to the structural analysis of the Zaire Basin. Tectonophysics vol. 194, p. 237263, 1991.

DEMEK, J. Geomorphological Mapping - progress and problems. In: Sharma, H.S. (ed.), Perspectives in Geomorphology: Applied Geomorphology, New Delhi: Concept Publishing, p. 221-235, 1982.

DIETRICH W.E.; DUNNE, T. The channel head. In: Beven K. e Kirkby, M.J. (eds.), Channel Network Hydrology, Chichester: Wiley, p. 175-219, 1993.

ETCHEBEHERE, M.L.; SAAD, A.R.; FULFARO, J.V.; PERINOTTO, J.A.J. Aplicação do índice "Relação DeclividadeExtensão-RDE”, na Bacia do rio do Peixe (SP) para detecção de Deformações Neotectônicas. Geol. US Ser. Cient., São Paulo, vol. 4, p. 43-56, outubro 2004.

FOGAÇA, A.C.C.; SCHÖLL, W.U. Estratigrafia e tectônica das rochas arqueanas e proterozóicas da região de Guinda e Gouveia (MG). In: Anais do Congr. Bras. Geol. 33, 1984. Rio de Janeiro. Rio de Janeiro: SBG, vol.2, p. 2638-2653,1984. 
FONSECA, B.M. O uso do Sistema de Informações Geográficas na análise morfométrica e morfológica de bacias de drenagem na Serra do Espinhaço Meridional - MG. 2010. 93f. Dissertação de Mestrado em Análise Ambiental, programa de Pós-Graduação em Geografia, Instituto de Geociências, Universidade Federal de Minas Gerais, Belo Horizonte, MG.

FONSECA, B.M; AUGUSTIN, C.H.R.R. Use of GIS to calculate Hack Index as a basis for comparative geomorphologic analysis between two drainage basins: a case study from SE-Brazil. In: International Geographic Union Regional Geographic Conference - UGI 2011, 2011, Santiago. Abstracts International Geographic Union Regional Geographic Conference - UGI 2011. Santiago: Military Geographic Institute of Chile (IGM), vol. 1, p. 1-12, 2011.

FONSECA, B.M; AUGUSTIN, C.H.R.R.; BEZERRA, D.P. Análise de perfis longitudinais na bacia hidrográfica do alto Jequitinhonha - serra do Espinhaço Meridional/MG. Revista Eletrônica Territorium-Terram vol. 01, nº 02, p. 2-8 | Abr./ Set. - 2013/2014.

GERRARD, J. Geology and landforms. In: Burt, T.P.; Chorley, R.J.; Brunsden, D.; Cox, N.J.; Goudie, A.S. (eds) The History of the study of Landforms or the Development of Geomorphology, vol. 4, Bath: Geological Society Publishing house, chapter 2, p. 13-48, 2008.

GREGORY, K.J.; WALLING, D.E. Drainage form and processes: a geomorphological approach. London: Edward Arnold Ltd, 1983. 458p.

Gustavsson, M. Development of a Detailed Geomorphological Mapping System and GIS Database in Sweden. Faculty of Science and Technology 236. Digital Comprehensive Summaries of Uppsala Dissertations. Acta University, Uppsala, Sweden, 2006. 36 p.

HACK, J. T. Stream-profile analysis and stream-gradient index. Journal of Research of the United States Geological Survey vol. 1, no. 4, p. 421-429, 1973.

HACK, J. T. Interpretation of erosional topography in humid temperate regions. American Journal of Science, Bradley Volume vol. 258-A, p. 80-97, 1960.

HARBOR, J. Numerical modeling of the development of U-shaped valleys by glacial. Geological Society of America Bulletin 104, p. 1364-1375, 1992.

HARTWIG M.E.; RICCOMINI, C. Análise morfotectônica da região da Serra dos Órgãos, sudeste do Brasil. Revista Brasileira de Geomorfologia vol. 11, nº 1, p. 11-20, 2010.
HOBSON, R.D. Surface roughness in topography: quantitative approach. In: Chorley, R.J. (ed.), Spatial analysis in geomorphology, Methuen Young Books, p. 225-245, 1972.

HORTON, R.E. Erosional development of streams and their drainage basins: hydrophysical approach to quantitative morphology. Bulletin of the Geological Society of America n 56 , p. 275-370, 1945.

HOWARD, A.D. Drainage analysis in geologic interpretation: a summation. Bulletin of. Amer. Assoc. of. Petr. Geol. vol. 51, p. 2246-2259, 1967.

HURTREZ, J.E; LUCAZEAU, F. Lithological control on relief and hypsometry in the Herault drainage basin (France). Comptes Rendus l'Academie des Sciences - Earth and Planetary Sciences 328(10), p. 687-694, 1999.

INSTITUTO BRASILEIRO DE GEOGRAFIA E ESTATÍSTICA (IBGE). Folha Carbonita, Minas Gerais, Brasil. Rio de Janeiro, 1978. Carta Topográfica. Escala 1:100.000.

INSTITUTO BRASILEIRO DE GEOGRAFIA E ESTATÍSTICA (IBGE). Folha Corinto, Minas Gerais, Brasil. Rio de Janeiro, 1978. Carta Topográfica. Escala 1:100.000.

INSTITUTO BRASILEIRO DE GEOGRAFIA E ESTATÍSTICA (IBGE). Folha Curvelo, Minas Gerais, Brasil. Rio de Janeiro, 1978. Carta Topográfica. Escala 1:100.000.

INSTITUTO BRASILEIRO DE GEOGRAFIA E ESTATÍSTICA (IBGE). Folha Presidente Kubitschek, Minas Gerais, Brasil. Rio de Janeiro, 1978. Carta Topográfica. Escala 1:100.000.

INSTITUTO BRASILEIRO DE GEOGRAFIA E ESTATÍSTICA (IBGE). Folha Rio Vermelho, Minas Gerais, Brasil. Rio de Janeiro, 1978. Carta Topográfica. Escala 1:100.000.

INSTITUTO BRASILEIRO DE GEOGRAFIA E ESTATÍSTICA (IBGE). Folha Diamantina, Minas Gerais, Brasil. Rio de Janeiro, 1978. Carta Topográfica. Escala 1:100.000.

LAMB, M.P.; DIETRICH, W.E. The persistence of waterfalls in fractured rock. Geological Society of America Bulletin 121, p. 1123-1134, 2009. Downloaded from gsa bulletin.gsapubs.org on April 9, 2011. doi: 10.1130/B26482.1.

LEOPOLD, L. B; BULL, W.B. Base level, aggradation and grade. American Philosophical Society Proceedings vol. 123(nº 3), p. 168-202, 1979.

LEOPOLD, L. B; WOLMAN, M.G.; MILLER, J.P. Fluvial Processes in Geomorphology. San Francisco: Freeman, 1964. 522p. 
LIMA, C.S.; CORRÊA, A.C.B.; NASCIMENTO, N.R. Analysis of the morphometric parameters of the Rio Preto basin, Serra do Espinhaço (Minas Gerais, Brazil). UNESP, São Paulo: Geociências vol. 30, nº 1, p. 105-112, 2011.

LIU, C.C. A geologia estrutural do estado do Rio de Janeiro, vista através de imagens MSS do Landsat. In: Anais do Simpósio de Geologia 1, 1987, Rio de Janeiro. Rio de Janeiro: SBG, Núcleo RJ-ES, p. 164-168, 1987,

LUO, W; STEPINSKI, T. Litho-control of some geomorphic properties: an illustration from Kumaun Himalaya, India. Zeitschrift fur Geomorphologie 18(4), p. 460-471, 2008a.

LUO, W. Identification of geologic contrasts from landscape dissection pattern: An application to the Cascade Range, Oregon, USA. Geomorphology 99, p. 90-98, 2008b.

MAYER, L. Quantitative analysis of landforms: A way to delineate active tectonic structures. Oxford: Geomorphology Laboratory, Annual Technical Report, Department of Geology. 1992. 48 p.

McKEOWN, F.A.; JONES-CECIL, M.; ASKEW, B.L.; McGRATH, M.B. Analysis of stream-profile data and inferred tectonic activity, Eastern Ozark Mountains region. U. S. Geological Survey Bulletin n ${ }^{\circ}$ 1807, p. 1-39, 1988.

MILLER, J.R.; RITTER, D.F.; KOCHEL, R.G. Morphometric Assessment of Lithologic Controls on Drainage Basin Evolution in the Crawford Upland, South-Central Indiana. American Journal of Science vol. 290, p. 569-599, May 1990.

MORISAWA, M. Fluvial Geomorphology (ed.). A Proceedings Volume of the Fourth Annual Geomorphology Symposia Series Held at Binghampton. New York: George Allen \& Unwin, 3th edition, 1981. 310p.

KUMAR, N. Morphometric Analysis of River Catchments Using Remote Sensing and GIS (A Case Study of the Sukri River, Rajasthan). International Journal of Scientific and Research Publications vol. 3, Issue 6, June 2013, p. 1-6. ISSN 2250-3153 www.ijsrp.org.

O’LEARY, D.W.; FRIEDMAN, J.D.; POHN, H.A. Lineament, linear, lineation: some proposed new standards for old terms. Geological Society of America Bulletin vol. 87, p. 1463-1469, 1976.

PARETA, K.; PARETA, P. Quantitative Geomorphological Analysis of a Watershed of Ravi River Basin, India. H.P. International Journal of Remote Sensing and GIS vol. 1, Issue 1, p. 47-62, 2012. Consultado em 16.5.2014: Research Article ISSN 2277-9051. www.rpublishing.org.
PECKHAM, S.D. Geomorphometry and spatial hydrologic modeling, In: Hengl, T. and Reuter, H.I. (eds), Geomorphometry: Concepts, Software and Applications. London: Elsevier, Chapter 25, Developments in Soil Science, vol. 33, p. 579-602, 2009.

PECKHAM, S. D. Profile, plan and streamline curvature: A simple derivation and applications. Proceedings of Geomorphometry, Redlands, CA, p. 27-30, 2011.

PENCK, W. Morphological Analysis of Landforms. London: McMillan. 1953. 429p.

PIRES NETO, A.G. As abordagens sintético-histórica e analítico-dinâmica: uma proposição metodológica para a geomorfologia. 1991. 302f. Tese de Doutoramento, Departamento de Geografia- USP. São Paulo, SP.

PORTILHO S. Perda de solo por escoamento superficial e os padrões de infiltração e percolação da água no solo, microbacia do Córrego Quebra, Gouveia, Espinhaço Meridional, MG. 2003. 117f. Dissertação de Mestrado, Instituto de Geociências, Universidade Federal de Minas Gerais. Belo Horizonte, MG.

RAO, G.T.; RAO, V.; DHAKATE, R.; RAO, S.T.M; RAJA RAO, M.B. Remote Sensing and GIS based Comparative Morphometric Study of Two Sub-watershed of Different Physiographic Conditions, West Godavari District, A.P. GT. Geological Society of India 79, p. 383-390, 2012.

REED, J.C.; SIGAFOOS, R.S.; FISHER, G.W. The river and the rocks; the geologic story of Great Falls and the Potomac River Gorge: US. Geological Survey Bulletin, 1471, 1980. 75 p.

ROSS, J.L.S. O registro cartográfico dos fatos geomórficos e a questão da taxonomia do relevo. Revista do Departamento de Cartografi, $n^{\circ}$ 6, 1992.

SAADI, A.A. Geomorfologia da Serra do Espinhaço em Minas Gerais e suas margens. Geonomos 3(1), p. 41-63, 1995.

SILVEIRA, C.S.; RAMOS, J.A. Análise espacial com SIG de parâmetros ambientais e comportamento hidrológico (chuvavazão) de uma bacia de drenagem montyanhosa na Serra dos órgãos: Bacia do Pauqequer, município de Teresópolis, R.J. Revista Brasileira de Geomorfologia, vol. 8, $n^{\circ}$ 1, p. 23-34, 2007.

SALLUN, A.E.M.; SUGUIO, K. Geoprocessamento na análise morfoestrutural da região entre Marília e Presidente Prudente (SP). In: Anais XIII Simpósio Brasileiro de Sensoriamento Remoto, Florianópolis, Brasil, INPE, 2007. 
SAMPAIO, T.V.M.; AUGUSTIN, C.H.R.R. Análise das incongruências dos índices de dissecação e rugosidade. In: Anais do VII Encontro Nacional de Geomorfologia-SINAGEO. Belo Horizonte, 2008.

SAMPAIO, T.V.M.; AUGUSTIN, C.H.R.R. Índice de concentração da rugosidade: uma nova proposta metodológica para o mapeamento e quantificação da dissecação do relevo como subsídio a cartografia geomorfológica. Revista Brasileira de Geomorfologia vol.15, n.1, p. 47-60, (Jan-Mar) 2014.

SANTOS, L.F.F.; GUEDES, I.C.; ETCHEBEHERE, M.L.C. Análise neotectônica do Pontal do Paranapanema (SP) mediante aplicação de parâmetros fluviomorfométricos. São Paulo, UNESP, Geociências vol. 30, nº 4, p. 491-507, 2011.

SCHUMM, S.A. Evolution of drainage systems and slopes in badlands of Perth Amboy. Geological Society of America Bulletin no 67, p. 597-646, 1956.

STRAHLER, A.N. Dynamic basis of Geomorphology. Geological Society of America Bulletin vol. 63, nº 9, p. 923938, 1952a.

STRAHLER, A.N. Hypsometric (area-altitude) analysis of erosional topology. Geological Society of America Bulletin 63, no. 11, p. 1117-1142, 1952 b.

STRAHLER, A.N. Quantitative analysis of watershed geomorphology. Transactions of the American Geophysical Union 38(6), p. 913-920, 1957.

SUMMERFIELD, M.A. Tectonics Geomorphology. Progress in Physical Geography 15(2), p.193-205, 1991.

TUCKER G.E.; HANCOCK, G.R. Modelling landscape evolution. Earth Surface Processes and Landforms vol. 35, p. 28-50, 2010. doi: 10.1002/esp.
UHLEIN, A. Transição cráton-faixa dobrada: exemplo do Cráton do São Francisco e da Faixa Araçuaí (Ciclo Brasiliano) no Estado de Minas Gerais. Aspectos estratigráficos e estruturais. 1991. 295f. Tese de Doutorado - Instituto de Geociências, Universidade de São Paulo, São Paulo, USP. São Paulo. SP.

VALERIANO, M.M.; CARVALHO JUNIOR, O.A. Geoprocessamento de Modelos Digitais de Elevação para mapeamento de curvaturas horizontal de microbacias. Revista Brasileira de Geomorfologia vol. 4, nº 1, p.17-29, 2003.

VAN DER BEEK, P.; BRAUN, J. Numerical modelling of landscape evolution on geological time-scales: a parameter analysis and comparison with the south-eastern highlands of Australia. Basin Research vol. 10, p. 49-68, 1998. doi: 10.1046/j.1365-2117.1998.00056.x.

VENEZIANI, P. Análise de movimentos da tectônica rúptil e rúptil-dúctil através da interpretação de produtos de sensores remotos na região do Espinhaço Meridional (MG): uma correlação com processos evolutivos. Tese de Doutorado. 1987. $186 f$ - Instituto de Geociências, Universidade de São Paulo, São Paulo. SP.

WHIPPLE, K.X; HANCOCK, G.S; ANDRESON, R.S. River incision into bedrock: Mechanics and relative efficacy of plucking, abrasion, and cavitation. Geological Society of America Bulletin 112(3), p. 490-503, 2000.

WAIKAR, M.L.; NILAWAR, A.P. Morphometric Analysis of a Drainage Basin Using Geographical Information System: A Case study. International Journal of Multidisciplinary and Current Research, p. 179-184, Jan/Feb 2014. Research Article: ISSN: 2321-3124. Disponível em: http://ijmcr.com

ZAVOIANU, I. Morphometry of Drainage Basin. Elsevier: New York, $2^{\text {nd }}$ edition. 1985. 238p. 